\title{
Psychological, Sociocultural, and Biological Elucidations for Gender Gap in STEM Education: A Call for Translation of Research into Evidence- Based Interventions
}

\author{
Ashraf Alam ${ }^{1, *}$ \\ ${ }^{1}$ Rekhi Centre of Excellence for the Science of Happiness, Indian Institute of Technology Kharagpur, India \\ *Corresponding author.Email: ashraf_alam@kgpian.iitkgp.ac.in
}

\begin{abstract}
Despite recent progress in narrowing gender gap in enrolment in math courses and relative achievements therein, girls and women still remain underrepresented when it comes to formal education in math-intensive academic fields such as engineering, mathematics, technology, and science, often referred to as STEM. Capacity to undertake a job and also the drive to put scientific and mathematical aptitude to use are both included in career paths. Individual variations in cognitive capability and motivation are impacted by a variety of sociocultural variables. The authors have presented six explanations for girl's inadequate representation in math-intensive STEM professions after analysing academic researches carried out in last three decades in domains of education, economics, sociology, and psychology: (a) preconceptions and biases based on gender, (b) field-specific ability beliefs, (c) lifestyle values or work-family balance preferences, (d) professional inclinations or desires, (e) comparative cerebral capabilities, and (f) cognitive aptitude. The study goes on to discuss sociocultural and biological causes for reported gender differences in motivational and cognitive factors, as well as the evolutionary period(s) during which each variable became most important. Authors concludes with evidence and scientific-proof based research, policy and practise suggestions for improving STEM inclusivity, and gives recommendations and directions for forthcoming researches.
\end{abstract}

Keywords: STEM education; Learning, Relative cognitive strength; Teaching, Career preference; Lifestyle value; Motivation; Gender gap, Pedagogy, Curriculum.

\section{INTRODUCTION}

In today's day and age, females are grossly underrepresented in engineering, mathematics, science, and technology (STEM) education [1-2]. According to survey results on undergraduate degrees awarded, girls are awarded more degrees (in percentage terms) in life sciences, however they are awarded a small percentage of degrees in mathematically-loaded disciplines such as technological and physical sciences, information and computer sciences, engineering, statistics, and mathematics [3-5]. Females are underrepresented in universities as well, with fewer doctorates awarded in technical and physical sciences, engineering, and information and computer sciences to females when compared with males [6-8]. Previous study has revealed that womankind in mathematically-loaded STEM fields lag far behind their male contemporaries [9-11]. Women remain to be represented inadequately in mathematically-loaded professions, according to social cognition specialists from around the world, who have created and contested theories to explain reasons behind it [1215]. Women folk are less probable compared with men to follow mathematically-loaded careers owing to lesser science and mathematics expectations and standards, while mindset theory advocates that woman are additionally vulnerable to abridged mathematics functioning in milieu of sanctioning a static outlook in mathematical aptitude [16-19]. As a result, author adopts a globally accepted social cognitive approach to elucidate females' inadequate representation in mathematically-loaded professions, 
acknowledging inherent benefits of utilizing different theoretically orientated explanations to elucidate men/women disparities in job preferences.

A broader social cognitive approach defines work pathways as having both ability and motivation to pursue a professional career [20-23]. It is probable that pursuing a STEM-related career will be difficult if one does not excel in math and science [24-25]. On the other hand, being able to solve math and scientific problems does not guarantee that a person will appreciate STEM-related activity or follow a STEM profession [26-28]. As a result, in addition to mental ability, competency evaluations, preferences, and values that one connects to important subject areas have a significant impact on job choice [29-31]. STEM occupations are considerably more likely to be followed by individuals who believe they are educated and enthusiastic about science and mathematics [32-35]. People's ideas, beliefs, objectives, aspirations, social identities, capacity to flourish, and connection to others are exposed through interactions and experiences in various situations [36-38]. These social connections and experiences build over a person's lifetime, influencing intellectual abilities and commitment, and, in line, deciding professional selections [29-31].

The primary aim of this research paper is to explain psychological, sociocultural, and cognitive variables that has an effect upon females' choices to pursue STEM careers that require a lot of mathematics. After that, the article examines social and biological causes that lead to observed gender differences in motivational and cognitive components. The article goes on to describe when each of these characteristics becomes even more significant across various evolutionary eras. It then offers empirically supported scientific proof-based practice and policy recommendations for improving female preconceptions and desire to participate in STEM, as well as retaining and accommodating a grander women labour force, by combining more adaptable, family-oriented, flexible, versatile, and dynamic workplace guidelines and programs. Finally, there are suggestions, guidelines, and study ideas to help us better grasp and understand gender-based societal issues in STEM education.

\section{STEM GENDER GAP: EVIDENCE- BASED REASONING}

Author identified six empirically confirmed variables as primary reasons of female inadequate representation in STEM fields, making use of social cognitive method as a conceptual framework:
Assumptions and biases based on gender, (b) aptitude assessments for specific professions, (c) lifestyle preferences, (d) career choices, (e) cognitive capacity, and (f) relative perceptual strengths. Motivational variables such as field-specific ability beliefs, lifestyle choices, and career preferences reflect personal interests, values, objectives, and attitudes, whereas relative cognitive strengths and cognitive ability are cognitive factors that indicate competence in mathematical and verbal reasoning ability.

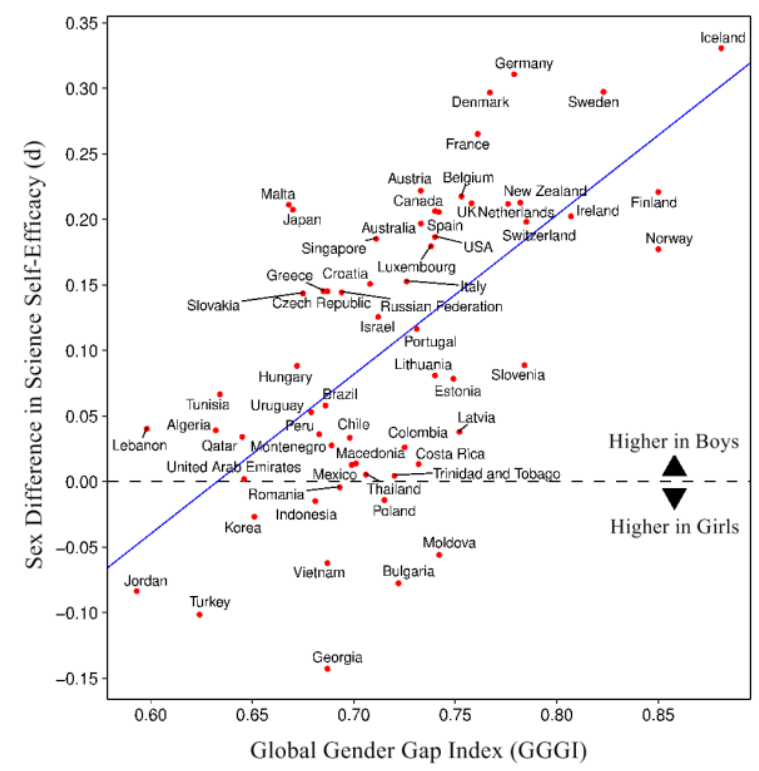

Figure 1 Gendered differences in self-efficacy science increases with increase in GGGI (adapted from [32-37])

\section{STEREOTYPES AND PREJUDICES BASED ON GENDER}

The degree to which prejudice and discrimination provide for females' inadequate representation in mathematically-loaded professions is a highly contested issue [1-3,9]. Researchers searched for gender discrimination research that was consistent or apparent across a range of STEM fields [13-17, 23]. They discovered no indication of bias or discrimination against women as they began or advanced in their scientific investigation, leading them to conclude that preconception and unfair treatment are historic instead of contemporary causal agent of female's inadequate representation in STEM areas. They also concluded that prejudice, bias, bigoted, and unfair conduct are in all likelihood emerge when girls and boys are beginning to define their occupational objectives. Gender discrimination was often described as an existent recruiting and 
promotion process, according to their study, especially among major research organizations [7-11, 31]. As a consequence, they were unable to differentiate between covert and overt types of prejudiced treatment, unable to examine the degree to which discriminatory or abusive behaviour towards members of opposite sex are prevalent on a day-today basis in professional and educational contexts, and decipher reasons for development of gendered mathematical and scientific discourses.

Denial of discrimination, animosity toward women who seek equality, and resentment of particular privileges conferred on women in order to achieve equality have long been distinguished from covert or subtle forms of gender discrimination [28, 36]. Experts on discrimination have also highlighted distinctions between violent and moderate types of sexism [27, 33, 39]. Both versions contain ideas that men should control women, but benign versions include loving attitudes and actions toward women, whereas hostile versions include insulting and exploitative opinions and actions towards adult female (for example, male as wage-earner and guardian, female as care giver).

We contend that the educational gender equality issue is caused by two processes, one based on distant social variables and the other on more proximate factors. These include a student's rational decisionmaking based on relative academic strengths and limitations, as well as attitudes that can be influenced by outside circumstances (Figure 2). Distal circumstances, such as extremely destitute living situations, may have an influence on the development of personal academic capabilities and attitudes toward various academic disciplines, culminating in secondary school, university education, and occupational choices.

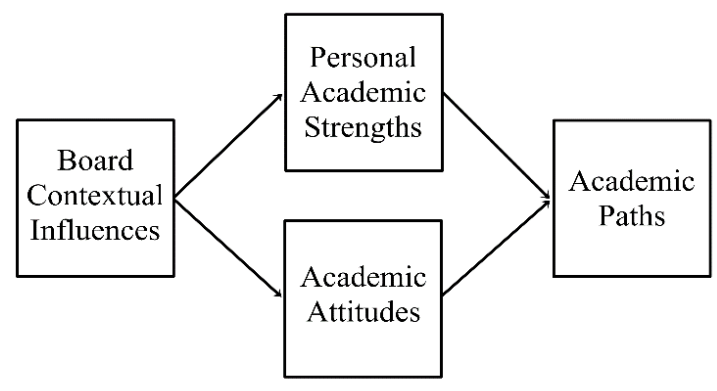

Distal Proximal Choices

Figure 2 Factors influencing educational and professional choices (adapted from [23-27, 36]).

Despite the fact that overt or deliberate acts of discrimination are less frequent today than they 20-30 years back, hidden and benign categories of sexbased discrimination persist and recur across persons' lifetime, having a proven impact on male and female career paths [4-7]. According to numerous studies, despite similar grades, parents and instructors underestimate female arithmetic capability, support men more frequently in mathematical and scientific pursuance, and credit schoolboys' math achievements to talent, and failures to lack of effort [5, 7, 19]. Parents' backing for mathematics and scientific learning begins at an early age, with mothers and fathers talking and explicating scientific materials to male child more frequently than to their female child, in spite of no gender dissimilarities in frequency of child-pioneered scientific cues [24, 29, 36]. Even if parents and instructors are not consciously or purposefully promoting stereotypes, girls' gender experiences with science and mathematics convey the notion that science and mathematics are those academic subjects that are dominated by men $[19,24$, 35].

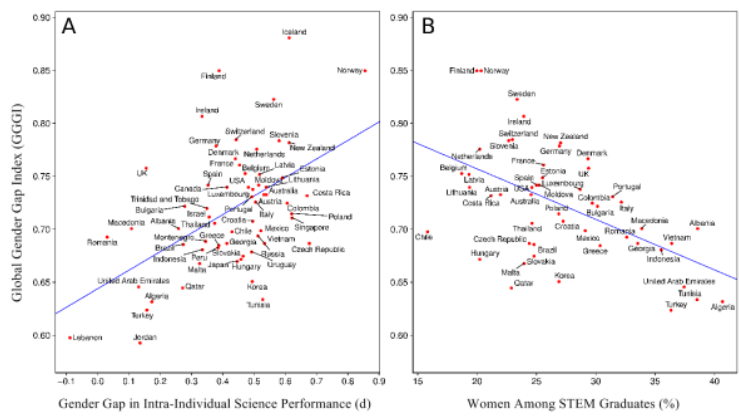

Figure 3 Gender equality is associated with intraindividual differences in science ability and STEM graduation. GGGI assesses the equality of men and women in economic, educational, health, and political opportunities. Blue lines represent regressions. A: Gender gap in intraindividual science scores is larger in more gender equal nations (rs $=.42$ ). B: Countries with more gender equality had a lower percentage of women with STEM degrees ( $\mathrm{rs}=$ -.47) [2, 37-39].

As youngsters get older, friends play an increasingly important role in shaping their STEM courses and future decisions [5-8]. Peer groups that support, advocate for, or model outstanding math and scientific performance are more likely to enrol in more math courses, have higher math and science excitement, and see themselves as future scientists [13-17]. While there is a continuous relationship between interaction among peers and girls' mathematical and scientific activities and attitudes in general, there is a somewhat greater connection between peers' interaction and girls' science and math 
activities and attitudes in particular [28-32]. In other words, since gender stereotypes are prominent in STEM areas, females may be more vulnerable to peer social pressures, that may prove to be damaging if compeers do not support scientific and mathematical aspirations of girls.

Furthermore, there are witnesses to testify for unconscious or subconscious prejudice towards female scientists in higher educational settings [3537]. When author's name is female rather than male, college students are more inclined to assess comparable conference papers as having a lower scientific merit, particularly if topics were typically having masculine themes [24-28]. According to many recent studies, academics are prejudiced implicitly in favour of recruiting men for faculty jobs [11-15]. Despite having identical merit in their application form, women seeking employment for research lab management job were regarded as less competent and consequently less hireable than male prospects. Another research showed that when male and female candidates with comparable mathematical abilities gave applications for a hypothetical employment position, males were having double probability of being employed compared to females [23-29]. Though this investigation was unable to show how these beliefs lead to discriminatory action, it does indicate that assumptions and unconscious prejudices affect women's interest in science. It's been shown, for example, that so called masculine academic disciplines like computational sciences may discourage women because of deficiency in belonging and apparent resemblance, and that eliminating stereotypic masculinist things from computational engineering courses can truly upsurge women's curiosity in such mathematically intensive STEM subjects [31-35]. While there is no compelling evidence of covert discrimination in recruitment and promotion of women at large research institutions, gendered stereotypical beliefs and unspoken genderbased predispositions may discourage several young women from taking up STEM intensive professions, thereby making these sectors "male-dominated" [2429].

\section{BELIEFS IN A PARTICULAR FIELD'S ABILITIES}

In their study, researchers [19, 22, 31] discovered that field-specific aptitude assumptions are elucidations for females' scarcity in mathematicallyloaded professions. Male-dominated sectors are more likely to be regarded as needing inherent intellect or genius than ones with a higher female presence.
These findings were similar across disciplines, signifying that gendered distribution is influenced by both interest in STEM subjects as well as by magnitude of innate intellect required for professional success. There has been a lot of study done on impact of effort versus intellect on women's motivation. Intelligence is viewed as a permanent trait or inherent skill in a fixed mentality, whereas intelligence is seen as malleable and may be gained over time through hard work, practice, and patience in a growth mindset $[21,34,39]$. People with fixed mindsets and growth mindsets have varied academic results, according to decades of study. Teenagers with growth mindsets outperformed those with fixed mindsets in terms of rates of successful completion and academic performance in stimulating mathematical lessons, according to research $[11,21,29]$. Students who have evolutionary attitude and growth mindset are highly expected to persevere in appearance of hardship, whereas students who have a fixed mindset are highly probable to easily quit owing to anticipation of unmet expectations $[5,14,23]$. Females perform worse than boys when faced with complicated mathematical content, and they are more prone than boys to suffer from poor arithmetic functioning when their mindset is fixed [12, 29, 37]. These discoveries recommend that females try to evade thought-provoking and stimulating STEM professions, both because they inaccurately assume that inborn astuteness is desired for accomplishing victory, and also because they feel that they come from an assemblage that has a very small probability of possessing requisite potentials and abilities.

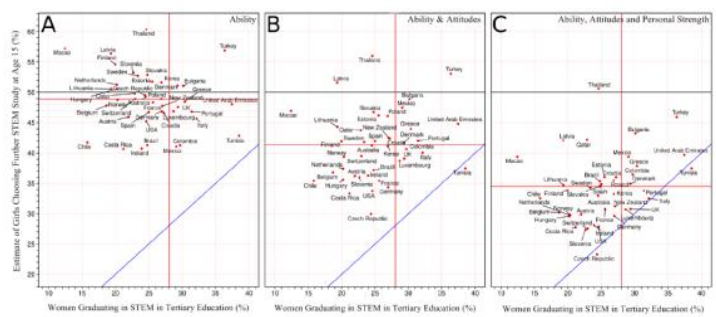

Figure 4 Female STEM higher education estimates based on secondary school ability and attitude criterion (adapted from [8-13, 28, 35, 39]).

Mentality has been researched in a number of educational settings, from elementary to postsecondary. When children move from elementary to secondary school, their attitude have a larger impact on their academic achievement. Unlike elementary school, where mastery takes priority over performance, learning environment in secondary and higher secondary school has high probability to motivate pupils to attain their performance 
objectives. Similarly, secondary and higher secondary school settings has high probability to encourage competitiveness, utilizing pre-set standards to assess learner achievement, and stressing on scoring high scores in standardized tests [12-15]. These changes are assumed to contribute to a decrease in teenage motivation and academic performance.

\section{BIOLOGICAL AND SOCIETAL CAUSES}

Learning objectives and attitudes do not develop in a vacuum. According to studies, mind is flexible and sensitive to social influences [31-34, 37]. Students in courses where content mastery rather than relative performance is emphasized, for example, are more motivated to push themselves, extend their knowledge, and achieve greater levels of success. Students in performance-oriented courses, on the other hand, are more inclined to overlook difficult issues and make more compromises [24, 27, 33]. This study showed that instructors' personal learning goals and mindsets may have a substantial impact on students' attitudes and overall academic performance. Children were more likely to persevere with difficult activities, enjoy activity more, do better in assignments, and support learning objectives rather than performance goals when experimenters complimented their effort rather than their ability, according to research $[7,23,38]$.

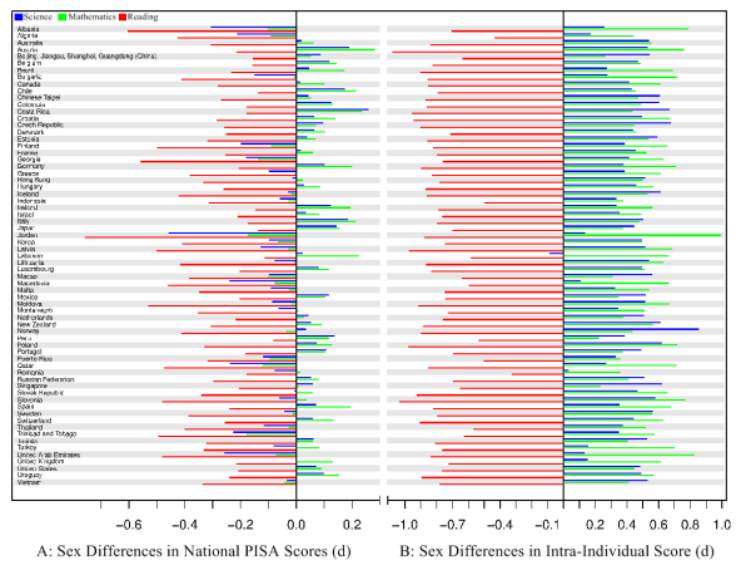

Figure 5 Cohen's d measures gender disparities in PISA science, mathematics, and reading scores. A: Differences in absolute PISA scores between men and women. B: Intra-individual score disparities by gender (adapted from [2, 7, 12-17, 24, 38]).

Furthermore, at a junior high school, interventions promoting a growth mindset improved student endorsement, math motivation, and math performance: intervention gains in mathematics achievement paths were higher for adolescents who formerly supported a static mentality. Dweck showed that growth mindset training benefitted girls more than boys, decreasing apparent gender disparities in arithmetic ability that were observed in control group $[8,23]$. According to this study, if larger prominence is positioned on merit of rehearsal, hard-work, and determination in arithmetic ability, females are highly probable to follow mathematically-loaded STEM vocations.

\section{WORK-LIFE-FAMILY BALANCE RELATED VALUES}

Gender inequalities in lifestyle choices, or relative significance of family vs. work for men and women, is the fourth component. Not only are women more willing than males to accept professional sacrifices for their families, but they also select work-cantered lives at a lower rate than men [23, 31, 39, 40]. Many women regard STEM vocations, or full-time faculty positions usually inappropriate for attaining their parenting objectives because their peak years of fertility and tenure ambitions coincide [23, 29, 39]. Despite the fact that women with children valued job flexibility more than men without children, men with families made comparable choices to those without children. These results indicate that when highly competent women become mothers, their lifestyle objectives may shift to concentrate more towards their family.

Choices in gendered lifestyle frequently develop post their teenage, when women and men encounter major life events (such as marriage and children) that allow them to assess how their occupations fit with their personal objectives [6, 23, 37]. Additional obstacles to women's STEM achievement arise when women opt to prioritize family obligations. To be productive and competitive, STEM professions need a substantial time commitment as well as ongoing professional development. Women with children work for lesser hours compared to men without or with children, whereas womenfolk without kids also work fewer hours compared to men without or with children [11, 19, 31]. Furthermore, owing to unique characteristics of STEM professions, it is problematic for womenfolk to go for pregnancy and rearing leave and at the same time maintaining efficiency echelons similar to their childless female and male colleagues $[18,25,37]$. As a consequence, these discoveries help in elucidating reasons for women being less likely than males to pursue mathematically-loaded 
professions and, as a result, they eventually quit these vocations.

\section{SOCIAL, CULTURAL, AND BIOLOGICAL REASONS}

Relative contributions of biological and social factors in generating male/female inequalities in family life choices are difficult to discern. Despite the fact that most civilizations split work responsibilities by gender to reflect women's reproductive capacity, extent of this separation varies by cultural ethos and level of rigidness of prevalent patriarchate $[4,19,21$, 29]. Despite gains achieved by women's rights organizations in 1970s, societal conventions and prejudices still dictate that women in United States are mainly responsible for childcare and housework. Women in mathematically-loaded STEM courses find it challenging to spend time required to stay up with newest advancements and remain successful in profession owing to societal constraints and personal decisions $[12-15,36]$.

\section{PREFERENCES IN CAREER}

Women's inadequate representation in mathematically-loaded professions is compounded by gender disparities in career choices. According to a meta-analysis, menfolk favour working with objects, while womenfolk favour to work with persons [29, 36, 29-32]. There were statistically significant differences between men and women $(d=0.93)$. The effect sizes of males' larger curiosity and attention towards STEM (for example, mathematics, $\mathrm{d}=0.34$ and engineering, $\mathrm{d}=1.11$ ) and females' higher interest in community welfare focused professions $(\mathrm{d}$ $=0.68$ ) were substantial. Altruism may affect women's choices for socially oriented professions because women show a higher desire to serve others and better society than males [5, 19, 28, 32]. Many women shy away from STEM areas because they are considered to be incompatible with social objectives. Females are highly probable of seeking academic degrees that will draw attention to society or are those that are concerned with welfare of human beings, particularly in STEM fields. For example, women favour biological and environmental engineering over engineering disciplines of the likes of electrical or mechanical [11, 28, 34]. This research shows that ambitions may exceed capabilities even amongst womenfolk who desire to join vocations in STEM areas.

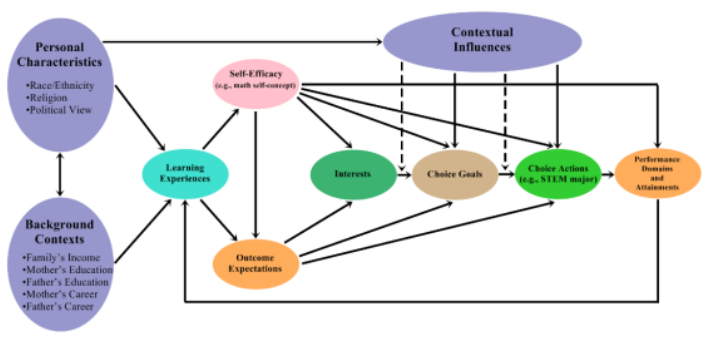

Figure 6 Model of career-related choice behaviour (adapted from [8, 21-25, 31-34, 39]).

Gender disparities in work choices and goals by late adolescence have been widely documented, while other research indicates that scientific career interests may be established as early as middle school $[7,13,17,21]$. Results of this study have far-reaching consequences for STEM career choices. High school is a critical age for choosing on a mathematicallyloaded professional path, particularly because students have greater flexibility to select courses that interest them. Advanced math courses are usually needed for admission to a mathematically-loaded STEM major in high school, and high school is a key age for choosing on a mathematically-loaded professional route $[2,7,29]$. Students' educational and professional interests may influence activities they choose to further improve, nurture, and expand their career interests prior to high school. Prior to high school, children's mathematical and scientific interests may assist to influence their future STEM job preferences, as well as educational experiences they choose throughout college and secondary schools, may help strengthen their interests with each passing year [21, 32, 39]. Certainly, gendered inequalities in STEM-based occupations, which echo variations in choices, may be traced back to infancy and are maintained through a never-ending cycle of decision-making, experience, and other people's expectations.

\section{SOCIOCULTURAL AND BIOLOGICAL STANDPOINTS ON GENDERED DIFFERENCES}

Interests and actions of men and women have long been studied in relation to biological and social variables. Women with congenital adrenal hyperplasia $(\mathrm{CAH})$, a disease induced by prenatal androgen exposure, amused herself with male toys more frequently than girls from control group in the study [11-16, 24]. Father or mother's approval and support to participate and enjoy with so-called masculine toys, on the other hand, decreased this connection, indicating that problems associated with 
socialization continues to have a significant role. While subjecting to androgen might alter dissimilarity in gendered predisposition, findings suggest that establishing social ties has an impact on gendered behaviour and likings [19, 26, 34]. Many women have been taught to accept that mathematically-loaded professions clash with their longing to socialize, which in all likelihood explains women's' lack of curiosity in STEM fields [17, 19, 25].

Males outperform females on high-stakes standardized exams, despite having better math abilities [2, 24, 32]. Recent meta-analyses found no statistically significant gendered divergences in arithmetic capability on a range of standardized tests, with modest mean effect sizes $(\mathrm{d}=0.15)$, which varied significantly with respect to research year, grade level, and nature of sample [6, 15, 31, 35-39].

Males scored significantly better towards rightmost tail of normal distribution, where numerous outstanding STEM employees are recruited, according to study, which extends findings beyond typical gender differences in standardized test performance [11, 27, 39]. Between 2006 and 2010, men outnumbered girls in top 0.01 percent of SAT and ACT math tests respectively by ratios $4: 1$ and $3: 1$. If cerebral aptitude degrees were the main reason for females' inadequate representation in mathematically-loaded industries, there would have been an equal number of male and female STEM employees. However, it is found that fewer women are pursuing mathematically-loaded professions and working in math-intensive companies (e.g., 4:1 or 25 percent women).

\section{STRENGTHS AND WEAKNESSES OF FEMALE AND MALE BRAINS}

Meanwhile, new evidence suggests that differences in cognitive breadth, rather than inequalities in fundamental cognitive aptitude, are to blame for gender gap in STEM [16, 23, 29-34]. That is, gender inequalities in STEM career choices are best explained by relative cognitive strengths rather than cognitive ability levels alone [7, 9, 23]. Bright people, according to this research, are more likely than the average population to possess a broad range of talents, which may influence their career choices. Individuals with better mathematical skills than those with poorer verbal abilities are highly probable to take up STEM professions, whereas those with equal verbal and mathematical capability are highly probable to choose non-STEM employment. Similarly, among mathematically gifted individuals, relative math and verbal performance is a strong predicter of domain where significant vocational achievements are probable to happen [14, 29, 31, 37]. People with advanced mathematical aptitude in comparison to verbal aptitude have greater chances to acquire a tenure-track professoriate post in STEM discipline and in securing a patent $[8,13,19,27]$. It is highly probable that females as compared to males will take up non-STEM occupations and achieve substantial professional success in non-STEM fields, even among mathematicians. It is highly probable that young woman will thrive in both verbal and mathematical capabilities, whereas men excel in arithmetic over verbal talents. Because women are more likely to be proficient in linguistic and mathematical skills, they may have more job options than males [11-16, 24].

Having a dominant cognitive talent leads to a positive self-perception of topic and a clear aim of devoting time, effort, and attention to studying that field as a probable option for vocation [21, 29, 36]. Many reasoning and perceptive skills, however, are more probable to direct to unclear expectations and conceptions about self, as well as fewer specified professional ends. Individuals with superior math skills than verbal abilities are highly probable to utilise these capability gaps as a criterion when choosing a mathematically-loaded job to capitalize on their chances to succeed $[19,26,38]$. Persons with equal verbal and mathematical aptitude (females have an additionally balanced linguistic and mathematical capabilities than males) are more inclined to put her/his likings and ideals over their talents, that explains the reason why females have additionally stable and composed verbal and arithmetic competencies than males $[19,25,36]$.

Gender differences in cognitive skills are difficult to anticipate because they emerge at a specific age. The aim here is to determine if there are any variations in cognitive capacity between men and women. Despite the fact that male child benefit from right-tail inequalities from playschool itself and girl child starts facing discriminations while moving towards pre-primary class, research indicates that gender difference in basic arithmetic aptitude remain small all over puerility and do not appear till late teenage years. While gender disparities in verbal aptitude diminish with time, inequalities in average verbal ability favouring females persist from kindergarten through infancy, according to the study. It's also unclear when gender variations in spatial orientation first emerged. Some studies (e.g., [11, 19, $24,36]$ ) showed superiority of men in tests having spatiality component, and are evidenced in them as 
early as during the beginning of kindergarten, while others (e.g., [8, 23, 29, 31, 38]) could not come up with any conclusive findings. Regardless of research differences, evidence indicates that gender disparities in cognitive skills emerge in early and late infancy, regardless of how stable or small they are, and thereby have important effects and influence, because this period of time corresponds with commencement of schooling. Gender disparities in cognitive performance may continue throughout a person's life as a result of their educational experiences from infancy through adolescence.

\section{EXPLANATIONS FROM A SOCIO- CULTURAL AND BIOLOGICAL PERSPECTIVE}

To better understand the relationship between gender and cognitive capacity, scientists looked at biological and cultural variables. Despite several studies in determining if genetic influences like for example brain lateralization and testosterone exposure are associated to robust math cognition and weak communication skills in men, results came out to be pretty inconsistent $[1,5-7,29]$. On the other hand, effects of sociological influence on gendered disparities in verbal and arithmetic capabilities are much more consistent. As a consequence of enhanced STEM-related learning experiences, even academics have demonstrated considerable STEM competence $[11,19,25,39]$. Father and mother can affect their kids' arithmetic expectations and academic grades by interacting with them about gendered views regarding how boys and girls are expected to perform in mathematics. Parents who hold rigid genderedmathematical stereotypic views (for example, males are superior at mathematics compared to females, and mathematics is quite essential and vital to men than to women) had superior views about their sons' arithmetic aptitude and poorer preconceived realisation of their daughters' mathematical capability. Such views of parents were later linked to children's assessments of their own arithmetic skills.

Furthermore, a number of research studies extending across territorial jurisdictions of nations have indicated that bigger sociocultural inequalities amongst men and women are linked with greater variations in arithmetic ability favouring men [9, 23, 32]. Women rarely approve typecast that science and mathematics are male-dominated subjects, particularly in countries where there are more females registered for science subjects and working in science and math related occupations. Such sociocultural norms and predispositions about men and women talents and responsibilities are taught to youngsters by well-known individuals. According to a meta-analytic study, parents' gendered preconceptions about female/male hobbies, skills and, interests are associated with kids' gendered cognitive schema about other individuals, and views on gendered professional engagements. Gender disparities in verbal performance favouring females, similar to gendered variances in mathematical aptitude, may be affected partly by early parenting. According to research, mothers speak to their daughters more frequently and with more encouraging words than they do to their boys $[5,23$, 39]. Other studies [12, 23, 38] showed that parents spend more time teaching their daughters verbal abilities like storytelling and reading, and few of such disparities started in puerility and lasted through primary school. Although these gender differences in socialization were not linked to cognitive performance in this study, they may assist to explain why girls outperform boys on standardized verbal ability tests. As a result, while biological effects cannot be ruled out completely, social variables have a greater impact on gender differences in cognitive capacity.

Finally, because they have more choices, people having greater symmetric cerebral contours in mathematics and verbal fields, as well as women with symmetrical profiles, are highly probable to take up non-STEM vocations [16, 24, 32, 39]. Why are women quitting mathematically-loaded jobs at such a high rate when there are so many other options? If equal cognitive capacity fully explained this phenomenon, women with strong math and language skills are equally probable to take up non-STEM and STEM vocations. Job choices are affected by extra motivators and selection factors. Main causes are gender variations in professional inclinations, family obligations/lifestyle standards, and field-specific competence expectations $[11,29,35]$.

\section{SUMMARY}

Gender biases and preconceptions, field-specific ability assumptions, lifestyle choices, career preferences, relative ability strengths, and absolute ability discrepancies all contribute to female inadequate representation in mathematically-loaded STEM fields. Lifestyle preferences, job choices, relative ability strengths, and absolute ability gaps have all been linked to variations in prenatal androgen exposure between men and women, with prenatal androgen exposure discrepancies being the most common. Sociocultural imperatives to take up 
customarily feminine or masculine interests (for example, "boys don't play with dolls"), and cultural views and customary hopes about men/women ability distinctness (e.g., males are rational, logical, and analytical, whereas females are frenetic, emotional, and sensitive), are much probable influencers of women's decisions for occupational selections. Aforementioned discoveries are disheartening because they show continuation of limited, erroneous, and inflexible notions of female or male in contemporary cultural milieu. Because social and cultural variables have a huge impact on individuals' employment choices, we may be able to intervene to alter these outcomes. The following part delves deeper into intervention techniques.

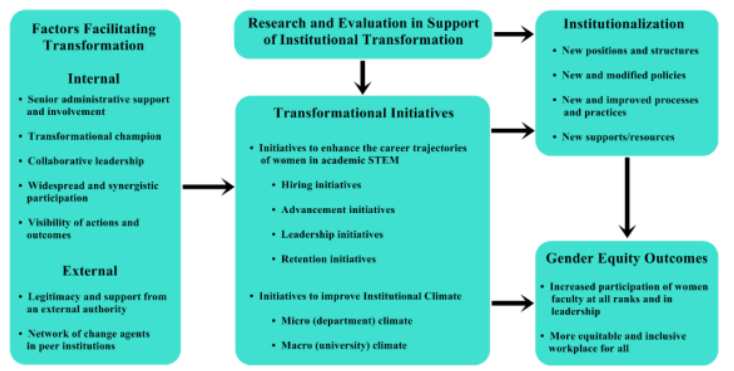

Figure 7 Institution's transformational framework to improve gendered justice in academical STEM (Adapted from [2-8, 23, 31-34]).

Appropriate time to intervene is decided by which of these six criteria is being evaluated, independent of necessity for action. Before kindergarten, boys gain from right-tail inequalities in mathematical ability, while girls benefit from gender differences in verbal ability and spatial connections [23, 29, 36]. Gender stereotypes and prejudice can emerge early in pregnancy, influencing parental behaviour ranging from clothing choices to toy purchases (for example, cars toys and train toys for boys; dolls and kitchen utensils for girls). As early as six years old, parents' traditional expectations, attitudes, and endorsements, as well as their own actions, affect their daughter's connections with mathematics and primary gendered individuality $[17,26,34]$. As a result, attitudes are formed in infancy and persist a lifetime. As the kid grows old, it becomes highly probable that he or she is to draw genuine connections between current interests and future possibilities, as well as deliberate decisions to engage in activities that advance their interests, possibly better preparing them for a STEM career. Changes in educational environments, such as schools becoming more performance-oriented rather than mastery-oriented, are especially detrimental to children in this age range. As a result, professional interests and aptitude assumptions become increasingly evident throughout 10-18 years and continue during senior secondary schooling. Lastly, daily regime choices do not appear to have a significant effect on women's STEM inadequate representation until they reach adulthood, when they have already chosen a STEM professional route and their STEM job starts to conflict with familial formulation and parenting obligations. Females' experiential participation in college/university (for example, as graduate and postdoctoral students) in workplace (for example, as tenure-track faculty members) will have a significant impact on their decision to pursue STEM professions.

\section{PROSPECTS FOR FUTURE RESEARCH}

In areas of STEM education, imbalances in gendered constructs must be addressed. Many studies have looked at gender difference between non-STEM and mathematically-loaded STEM professions, but only few have looked at gaps in gender in STEM disciplines and tried to answer reasons for women's selection of less mathematically-loaded STEM vocations.

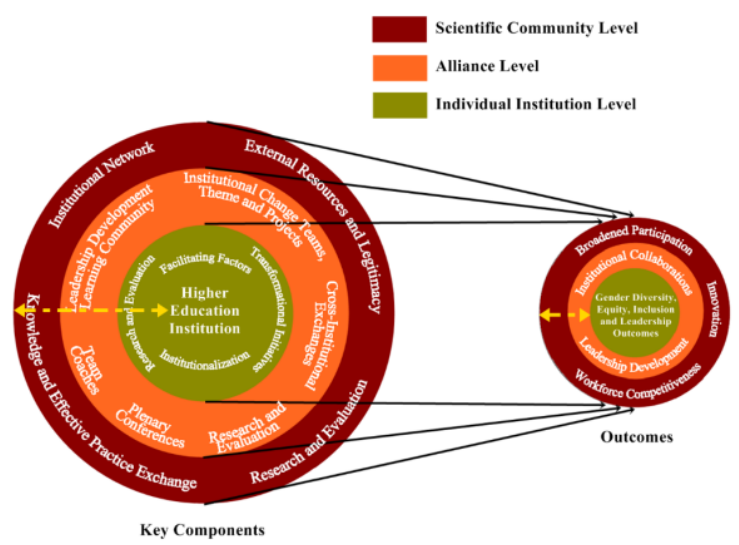

Figure 8 Integrative Model

In general, womenfolk are inadequately represented in STEM arenas, however degree of inadequate representation differs depending on nature of problem. Despite the fact that women currently account for a good proportion of medical doctors and $\mathrm{PhDs}$ in biological sciences, they remain inadequately represented in majority of mathematically-loaded STEM disciplines. Examining reasons that influence choice of entering into relatively less mathematically-loaded STEM professions vs. mathematically-loaded STEM professions is important. Is it true that women with comparable math and language abilities choose medicine over engineering? Is this because 
mathematically-loaded STEM is linked to agentic objectives, while less mathematically-loaded STEM is related with community service? To assess female engagement in STEM, researchers need to examine factors that contribute to separation of STEM disciplines, especially those with lowest total female participation.

\subsection{It is essential to highlight women from lower castes and religious minorities}

Despite numerous efforts aimed at reducing STEM gender gap, diversity among women is frequently discounted. Dalit and tribal women are inadequately represented in STEM as compared to women from higher castes. Women are frequently portrayed as a united group with similar goals, experiences, and cultural roots. As a result, many research investigations have isolated caste, race, and gender, thus obfuscating their multifaceted and intricate interconnections in historical settings. Due to their participation in two stigmatized groups, Dalit and tribal women suffer additional hostility, a condition commonly referred as "double jeopardy." This is specifically true in STEM areas, where caste and gender biases prevail. Despite their enthusiasm for study, statistics show that discrimination based on caste and gender frequently hinders dalit undergraduate women from pursuing science-related professions. Despite "double risk" that dalit and tribal girls face, research indicates that gender socialization in many dalit and tribal cultures may offer unique possibilities for female STEM workers. Women from tribal and dalit groups are more likely than uppercaste women to view work as an essential component of their family. As a result, dalit and tribal girls' gender socialization may shield them from apparent contradiction between family life and STEM occupations, which averts countless females from choosing STEM jobs. Future research should look into role of gender, tribe, and caste in female inadequate representation in STEM and develop policy solutions that are tailored to needs of this diverse community, given the unique challenges and protective factors that dalit and tribal females face in STEM settings.

\subsection{Convert research results into evidence- based therapy}

Several programs have been shown to enhance the attitudes of girls and women toward STEM. Despite the fact that research backs up concepts in this study, there is still a need to turn research-based knowledge into action. Which approach is most effective for promoting these program efforts: at home, at school, in peer groups, in media, or an amalgamation of four? If early interventions are carried out to increase females' curiosity in STEM, for how long do advantages of a program have to continue in order for it to be considered successful? Many recent researches have focused primarily on short-term impacts of intervention exposure on people's attitudes and performance.

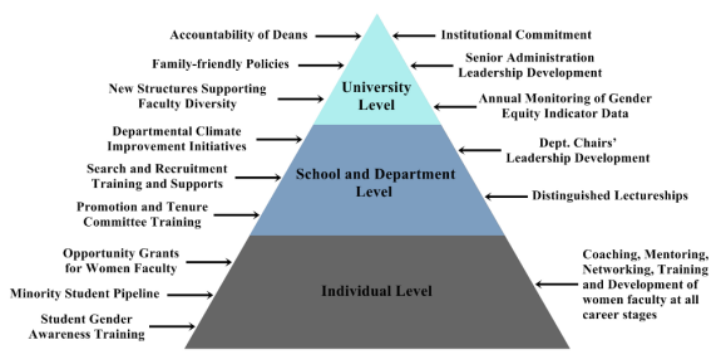

Figure 9 Effective practices for gender equity transformation (Modified from [19, 27, 36, 39]).

Women's professional interests and ambitions should be examined longitudinally in future to see if they lead to substantial changes. In addition, interventions should not be limited to changing attitudes of girls and women toward STEM, however it also ought to target STEM professors, parents, instructors, and employers in order to eliminate implied prejudice and preconceptions against female scientists. More comprehensive STEM program evaluations should include long-term follow-up, formation of assessment groups, and gathering data of inadvertent causal effects, for example, schematically amplified gendered behaviour as a result of introductory experience with female-specific STEM programmes.

\subsection{Significance of women participation in learning Science, Mathematics, and English}

There has been a lot of research on how verbal aptitude vs. math skills affect vocational preference. For scientific/mathematical/technological job profile (pragmatic, genuine, and analytical mind, strong selfconcept in spatial, mathematical, and scientific competencies) and intellectual/verbal job profile (investigative and creative interests), trait clusters predict domain-specific knowledge differently (investigative and creative interests). A deepened understanding of humanities, civics, biology, and psychology is related to a verbal/intellectual personality profile, while a deeper understanding of physical sciences and technology is linked to a science/math/technology personality profile. 
However, little is known about how men's and women's enthusiasm for science, math, and English is influenced by STEM educational and employment choices. Incorporating science and mathematics into a big science-mathematics component, or studying these academic disciplines separately in different models will restrict academic turf's capability to contrast their effects. It's difficult to tell whether a strong interest in math and physics is equally significant for selecting STEM, or whether a tall curiosity in one topic may compensate for a lack of curiosity in another topic. Moreover, because womenfolk are highly probable to take up less mathematically-loaded STEM fields, it will be useful to identify whether advanced mathematical competency and curiosity in learning science are prerequisite for mathematically-loaded STEM vocations, and whether greater interest in science and advanced mathematical competency are factors for less mathematically-loaded STEM vocations. To fully understand connection amongst motivational factors and domain-specific competence, more research is needed.

\subsection{Investigate connections between biological, psychological, and environmental variables}

Collaborative research models that take into consideration multifaceted reciprocal action and reaction of environmental, psychological, and biological causes, as well as how these variables intermingle to impact women professional selections and STEM achievement, are becoming increasingly significant. Separating social and psychological impacts from genomic endowment has been proved to be tough despite research aimed at identifying sociocultural and genetic stimuluses that influence gendered disparities in interests, skills, and career choices. These qualities clearly sum up to more than their parts; they build up and intermingle as time passes. Regardless of biological differences, investigation that combines social, genetic, and psychic variables that affect professional advancement may be able to better identify experiences and events that assist or hinder female STEM achievement.

\section{CONCLUDING REMARKS}

Gender gap in STEM education will be reduced by concentrating on appropriate cognitive, motivational, and social aspects, which will expand career choices that womenfolk remark as feasible and well-suited with their goals, interests, and talents. Till the time, misinformation, gender biases, and cultural barriers will continue to enable a substantial percentage of mathematically gifted women to slip through gaps. Our goal is to improve women's employment possibilities by removing misinformation, macho stereotypes, and other obstacles to professional opportunities, promoting female interest in science and math, emphasizing hard work and effort over ability, and demonstrating cognitive abilities. To accomplish these objectives, policymakers, practitioners, and academics will be required to enhance their communication and cooperation abilities [41]. Social scientists and researchers may help by critically examining available researches, developing models, research questions, and hypotheses testing. They shall provide evidence-based data to substantiate, alter, or discard these ideas. They must also communicate their results with practitioners and policymakers, who may eventually apply their discoveries into action by initiating macro-level campaigns to influence broader cultural sphere or interacting with girls on a microlevel to spark their curiosity and attention in STEM. Micro-level interventions at universities are necessary to eliminate non-family-friendly attitudes and institutional prejudice, while macro-level interventions are needed to improve daily experiences in educational settings for improved engagement of girl child. Research reflects policymakers' and practitioners' efforts, showing what works and what doesn't, and motivating academics to continue studying and improving these programs. As industry stakeholder cooperates more and women's chances in STEM improves, gender gap in STEM disciplines would continue to decrease.

\section{REFERENCES}

[1] Reilly, D., Neumann, D. L., \& Andrews, G. (2017). Gender differences in spatial ability: Implications for STEM education and approaches to reducing the gender gap for parents and educators. In Visual-spatial ability in STEM education (pp. 195-224). Springer, Cham.

[2] Verdugo-Castro, S., García-Holgado, A., \& Sánchez-Gómez, M. C. (2019, October). Analysis of instruments focused on gender gap in STEM education. In Proceedings of the Seventh International Conference on Technological Ecosystems for Enhancing Multiculturality (pp. 999-1006). 
[3] Beede, D. N., Julian, T. A., Langdon, D., McKittrick, G., Khan, B., \& Doms, M. E. (2011). Women in STEM: A gender gap to innovation. Economics and Statistics Administration Issue Brief, (04-11).

[4] García-Holgado, A., Verdugo-Castro, S., González, C., Sánchez-Gómez, M. C., \& GarcíaPeñalvo, F. J. (2020). European proposals to work in the gender gap in STEM: A systematic analysis. IEEE Revista Iberoamericana de Tecnologias del Aprendizaje, 15(3), 215-224.

[5] Ciftci, A., Topcu, M. S., \& Erdogan, I. (2020). Gender Gap and Career Choices in STEM Education: Turkey Sample. International Journal of Progressive Education, 16(3), 53-66.

[6] Chomphuphra, P., Chaipidech, P., \& Yuenyong, C. (2019, October). Trends and Research Issues of STEM Education: A Review of Academic Publications from 2007 to 2017. In Journal of Physics: Conference Series (Vol. 1340, No. 1, p. 012069). IOP Publishing.

[7] Tandrayen-Ragoobur, V., \& Gokulsing, D. (2021). Gender gap in STEM education and career choices: what matters?. Journal of Applied Research in Higher Education.

[8] Xie, Y., Fang, M., \& Shauman, K. (2015). STEM education. Annual review of sociology, 41, 331-357.

[9] García-Holgado, A., Verdugo-Castro, S., Sánchez-Gómez, M. C., \& García-Peñalvo, F. J. (2019, June). Trends in studies developed in Europe focused on the gender gap in STEM. In Proceedings of the XX International Conference on Human Computer Interaction (pp. 1-8).

[10] Chachashvili-Bolotin, S., Milner-Bolotin, M., \& Lissitsa, S. (2016). Examination of factors predicting secondary students' interest in tertiary STEM education. International Journal of Science Education, 38(3), 366-390.

[11] Beede, D., Julian, T., Langdon, D., McKittrick, G., Khan, B., \& Doms, M. (2011). Women in STEM: A Gender Gap to Innovation. ESA Issue Brief\# 04-11. US Department of Commerce.

[12] Brenøe, A. A., \& Zölitz, U. (2020). Exposure to more female peers widens the gender gap in stem participation. Journal of Labor Economics, 38(4), 1009-1054.
[13] Han, S. W. (2016). National education systems and gender gaps in STEM occupational expectations. International Journal of Educational Development, 49, 175-187.

[14] Schneider, B., Milesi, C., Brown, K., Gutin, I., \& Perez-Felkner, L. (2015). Does the gender gap in STEM majors vary by field and institutional selectivity?. Teachers College Record.

[15] García-Holgado, A., Mena, J., García-Peñalvo, F. J., Pascual, J., Heikkinen, M., Harmoinen, S., ... \& Amores, L. (2020, April). Gender equality in STEM programs: a proposal to analyse the situation of a university about the gender gap. In 2020 IEEE Global Engineering Education Conference (EDUCON) (pp. 1824-1830). IEEE.

[16] Verdugo-Castro, S., Sánchez-Gómez, M. C., \& García-Holgado, A. (2018, October). Gender gap in the STEM sector in pre and university studies of Europe associated with ethnic factors. In Proceedings of the Sixth International Conference on Technological Ecosystems for Enhancing Multiculturality (pp. 984-990).

[17] Raabe, I. J., Boda, Z., \& Stadtfeld, C. (2019). The social pipeline: How friend influence and peer exposure widen the STEM gender gap. Sociology of Education, 92(2), 105-123.

[18] Kuschel, K., Ettl, K., Díaz-García, C., \& Alsos, G. A. (2020). Stemming the gender gap in STEM entrepreneurship-insights into women's entrepreneurship in science, technology, engineering and mathematics. International Entrepreneurship and Management Journal, 16(1), 1-15.

[19] Jungert, T., Hubbard, K., Dedic, H., \& Rosenfield, S. (2019). Systemizing and the gender gap: examining academic achievement and perseverance in STEM. European Journal of Psychology of Education, 34(2), 479-500.

[20] Perez - Felkner, L. (2018). Conceptualizing the field: Higher education research on the STEM gender gap. New Directions for Institutional Research, 2018(179), 11-26.

[21] Arredondo Trapero, F. G., Vázquez Parra, J. C., \& Velázquez Sánchez, L. M. (2019). STEM and Gender Gap in Latin America. Revista de El Colegio de San Luis, 9(18), 137-158.

[22] Ismail, Z. (2018). Benefits of STEM education. 
[23] Khine, M. S. (2016). Visual-spatial ability in STEM education. Springer International $\mathrm{Pu}$.

[24] Zhou, Y., Fan, X., Wei, X., \& Tai, R. H. (2017). Gender gap among high achievers in math and implications for STEM pipeline. The AsiaPacific Education Researcher, 26(5), 259-269.

[25] Viadero, D. (2009). Researchers Mull STEM Gender Gap. Education Week, 28(35), 1-15.

[26] Levine, M., \& DiScenza, D. J. (2018). Sweet, sweet science: Addressing the gender gap in STEM disciplines through a one-day high school program in sugar chemistry. Journal of Chemical Education, 95(8), 1316-1322.

[27] Krämer, N. C., Karacora, B., Lucas, G., Dehghani, M., Rüther, G., \& Gratch, J. (2016). Closing the gender gap in STEM with friendly male instructors? On the effects of rapport behavior and gender of a virtual agent in an instructional interaction. Computers \& Education, 99, 1-13.

[28] Liben, L. S. (2015). The STEM gender gap: The case for spatial interventions. International Journal of Gender, Science and Technology, $7(2), 133-150$.

[29] Wang, M. T., \& Degol, J. L. (2017). Gender gap in science, technology, engineering, and mathematics (STEM): Current knowledge, implications for practice, policy, and future directions. Educational psychology review, 29(1), 119-140.

[30] Naizer, G. (2014). Narrowing the gender gap: Enduring changes in middle school students' attitude toward math, science and technology. Journal of STEM Education: Innovations and Research, 15(3).

[31] Faitar, G. M., \& Faitar, S. L. (2013). Gender gap and stem career choices in 21st century American education. Procedia-Social and Behavioral Sciences, 106, 1265-1270.

[32] Cardador, M. T., Damian, R. I., \& Wiegand, J. P. (2021). Does More Mean Less?: Interest Surplus and the Gender Gap in STEM Careers. Journal of Career Assessment, 29(1), 76-97.

[33] Screpanti, L., Cesaretti, L., Marchetti, L., Baione, A., Natalucci, I. N., \& Scaradozzi, D. (2018). An educational robotics activity to promote gender equality in STEM education. ICICTE 2018 Proceedings.
[34] Kanny, M. A., Sax, L. J., \& Riggers-Piehl, T. A. (2014). Investigating forty years of STEM research: How explanations for the gender gap have evolved over time. Journal of Women and Minorities in Science and Engineering, 20(2).

[35] Piva, E., \& Rovelli, P. (2021). Mind the gender gap: the impact of university education on the entrepreneurial entry of female and male STEM graduates. Small Business Economics, 1-19.

[36] Kim, D. H., \& Law, H. (2012). Gender gap in maths test scores in South Korea and Hong Kong: Role of family background and single-sex schooling. International Journal of Educational Development, 32(1), 92-103.

[37] García-Holgado, A., Verdugo-Castro, S., González, C., Sánchez-Gómez, M. C., \& GarcíaPeñalvo, F. J. (2020). European proposals to work in the gender gap in STEM: A systematic analysis. IEEE Revista Iberoamericana de Tecnologias del Aprendizaje, 15(3), 215-224.

[38] Setzekorn, K., Burton, T., Farrelly, C. M., \& Ferebee, S. S. (2020). Gender Gap: Factors Affecting Female Students' Retention in an Online Undergraduate IT Program. In Socioeconomics, Diversity, and the Politics of Online Education (pp. 79-89). IGI Global.

[39] Priulla, A., D'Angelo, N., \& Attanasio, M. (2021, July). Gender Differences In Stem Courses: Analysis Of Italian Students' Performance. In SCUOLA DEMOCRATICA.

[40]J Gochhayat, V.N. Giri, D. Suar, Multilevel leadership and organizational effectiveness in Indian technical education: the mediating role of communication, power and culture, International Journal of Leadership in Education 20(4) (2017) 491-505,

DOI: $10.1080 / 13603124.2015 .1135254$

[41] D Suar, J Gochhayat, Influence of biological sex and gender roles on ethicality, Journal of Business Ethics 134 (2), (2016) 199-208. 